\title{
Behavioral Activation in Rats Requires Endogenous Ascorbate Release in Striatum
}

\author{
George V. Rebec and Zhongrui Wang \\ Program in Neural Science, Department of Psychology, Indiana University Bloomington, Indiana 47405
}

Ascorbate (vitamin C) is found in high concentrations in the striatum in which it may play a role in behavioral activation. To test this hypothesis, freely behaving rats received bilateral intrastriatal infusions of ascorbate oxidase (AAO) to inactivate extracellular ascorbate. Slow-scan voltammetry was used simultaneously to assess changes in ascorbate and 3,4-dihydroxyphenylacetic acid (DOPAC), a major dopamine metabolite, near the infusion site. Intrastriatal AAO, but not saline vehicle, caused a rapid decline in both ascorbate and behavioral activation. Within $20 \mathrm{~min}$, an ascorbate loss of $50-70 \%$ led to a near-total inhibition of all recorded behavior, including open-field locomotion, approach of novel objects, and social interactions with other rats. DOPAC levels remained stable, arguing against an AAOinduced disruption of dopamine transmission. Consistent with this interpretation, subsequent injection of $1.0 \mathrm{mg} / \mathrm{kg} d$-amphetamine, an indirect dopamine agonist, quickly restored behavioral activation, which also was accompanied by a marked rise in extracellular ascorbate. Bilateral AAO infusions into dorsal hippocampus, which also has a high level of extracellular ascorbate, failed to alter behavioral activation, indicating that a loss of brain ascorbate per se does not suppress behavior. Collectively, these results implicate ascorbate in the behavioral operations of the striatum and suggest that the extracellular level of this vitamin plays a critical role in behavioral activation.

Key words: amphetamine; ascorbate; ascorbate oxidase; behavioral activation; dopamine; glutamate; striatum; vitamin C; voltammetry
As the primary integrative structure of the basal ganglia, the striatum has been implicated in simple movement, as well as complex cognitive and emotional responses (Calabresi et al., 1997; Redgrave et al., 1999). In accord with this broad behavioral role, the striatum processes information from the entire cortical mantle (Graybiel et al., 1994; Gerfen and Wilson, 1996). In fact, the release of glutamate from cortical afferents is the main source of striatal activation (Parent et al., 1995). Dopamine, which arises from nuclei in the ventral midbrain, exerts modulatory control by adjusting the strength of the glutamate response (Nicola et al., 2000). The significance of this modulation is evident in the many behavioral deficits linked to a disruption of striatal dopamine transmission (Zigmond et al., 1990; Spanagel and Weiss, 1999).

Another potentially important modulator of striatal function is ascorbate, a water-soluble vitamin known for its antioxidant properties (Halliwell, 1996; Rice, 2000). Although ascorbate is present in striatal extracellular fluid at $>1000$ times the concentration of dopamine (Basse-Tomusk and Rebec, 1991), increasing evidence suggests that, apart from scavenging free radicals, ascorbate influences synaptic function (Rebec and Pierce, 1994; O'Neill, 1995). Local applications of ascorbate, for example, enhance the response of striatal neurons to iontophoresis of either dopamine or glutamate (Pierce and Rebec, 1995; Kiyatkin and Rebec, 1998). This enhancement, moreover, is limited to the endogenous L-isomer, although both ascorbate isomers have equivalent antioxidant potency. It also is interesting that glutamate transport

\footnotetext{
Received June 26, 2000; revised Oct. 24, 2000; accepted Oct. 24, 2000.

This research was supported by National Institute of Neurological Disorders and Stroke Grant NS 35663. Dr. Dale Sengelaub prepared the bright-field photomicrograph. We also acknowledge the technical contributions of Paul Langley and the editorial assistance of Faye Caylor.

Correspondence should be addressed to George V. Rebec, Program in Neural Science, Psychology Building, 1101 E. Tenth Street, Indiana University, Bloomington, IN 47405-7007. E-mail: rebec@indiana.edu.

Copyright (C) 2001 Society for Neuroscience $\quad 0270-6474 / 01 / 210668-08 \$ 15.00 / 0$
}

appears to be the trigger for ascorbate release. Thus, intrastriatal infusions of glutamate promote the efflux of ascorbate into extracellular fluid (O’Neill et al., 1984; Ghasemzedah et al., 1991; Pierce and Rebec, 1993), and this effect is blocked by inhibition of glutamate transport (Cammack et al., 1991). Separate transporter proteins appear responsible for ascorbate removal (Tsukaguchi et al., 1999), indicating that extracellular ascorbate is under relatively precise control.

The level of striatal ascorbate fluctuates with behavioral activity such that the highest extracellular concentration appears during peak motor behavior (O'Neill and Fillenz, 1985). Consistent with this finding, the behavioral activation induced by amphetamine and other dopamine agonists is accompanied by a parallel increase in striatal ascorbate (Mueller, 1989; Pierce and Rebec, 1990). Although suggestive, such data do not establish a causal link between ascorbate release and behavioral activation. Some support comes from evidence that scorbutic guinea pigs suffer from behavioral depression, but this effect is confounded by the poor health of such animals (Kaufmann et al., 1986).

To make a direct assessment of the relationship between endogenous striatal ascorbate and behavior, we infused ascorbate oxidase (AAO), a dimeric copper-containing enzyme that metabolizes ascorbate, bilaterally into the striatum of rats tested in an open-field environment equipped with novel objects and populated with other rats. Motor activation patterns and their frequencies were assessed along with the frequency of approach of novel objects and social interactions. The extent of ascorbate depletion was monitored simultaneously with slow-scan voltammetry, which also measured 3,4-dihydroxyphenylacetic acid (DOPAC), a major dopamine metabolite. To assess the behavioral specificity of intrastriatal AAO, some rats received bilateral infusions into dorsal hippocampus, another forebrain structure with a high level of extracellular ascorbate. 


\section{MATERIALS AND METHODS}

Animals and surgery. Data were obtained from male, Sprague Dawley rats (300-400 gm), bred in the departmental animal colony from source animals supplied by Harlan Sprague Dawley (Indianapolis, IN). All rats were housed individually under standard laboratory conditions $(12 \mathrm{hr}$ light/dark cycle beginning at 7:00 A.M.) with access to food and water $a d$ libitum. All surgical and experimental procedures complied with guidelines established in the Guide for the Care and Use of Laboratory Animals (National Institutes of Health Publication 865-23); the animal-use protocol was approved by the Indiana University Bloomington Institutional Animal Care and Use Committee.

Surgery was performed while the animals were secured in a stereotaxic frame under chloropent anesthesia $(0.33 \mathrm{ml} / 100 \mathrm{gm}$, i.p. $)$. For voltammetric recording, the skull was prepared as described previously (Rebec et al., 1993) with a plastic hub secured over the right striatum $(\sim 1.0 \mathrm{~mm}$ anterior and $2.5 \mathrm{~mm}$ lateral to bregma). A stainless steel screw threaded into a distant site on the skull served as both auxiliary and reference electrodes and provided structural support for the working-electrode assembly, which was attached to the skull-mounted hub on the recording day. To allow for intrastriatal infusions, a small hole was drilled bilaterally ( $\sim 2.2 \mathrm{~mm}$ posterior and $\sim 2.8 \mathrm{~mm}$ lateral to bregma), and stainless steel infusion cannulas ( 26 gauge) were positioned at a $45^{\circ}$ angle toward the striatum and lowered at least $2 \mathrm{~mm}$ into overlying tissue. The plastic hub was sealed with a rubber stopper, and a wire stylet was inserted into both infusion cannulas to prevent clogging. Dental cement secured the hub and cannulas to the skull. For cases in which infusions were performed without voltammetry, infusion cannulas were positioned bilaterally on the skull directly over the striatum (see hub coordinates) or dorsal hippocampus ( $\sim 4.5 \mathrm{~mm}$ posterior and $2.5 \mathrm{~mm}$ lateral to bregma). All animals were returned to the home cage and allowed a 5-7 d recovery period, during which they were handled regularly by the experimenter to habituate them to this procedure.

Slow-scan voltammetry. Working electrodes were prepared from Thornell P-55 carbon fibers (Union Carbide, Danbury, CT) as described previously (Ewing et al., 1982). In each case, the active surface area was $150-200 \mu \mathrm{m}$ in length and $8-10 \mu \mathrm{m}$ in diameter. Standard electrochemical pretreatment permitted the discrimination of ascorbate from catechols, which in striatal extracellular fluid appear mainly as DOPAC (Gonon et al., 1980) and other easily oxidized compounds. To confirm its selectivity, each electrode was first tested voltammetrically in a solution containing $100 \mu \mathrm{M}$ ascorbate and $20 \mu \mathrm{M}$ DOPAC.

For in vivo recording, the working electrode was secured in a holder equipped with a luer-lock connector that mates with the skull-mounted hub (Rebec et al., 1993). A threaded assembly in the holder permitted 11 $\mathrm{mm}$ of dorsoventral electrode travel. The electrode was lowered $\sim 4.5 \mathrm{~mm}$ ventral to the brain surface into the striatum. Generation of waveforms for slow-scan staircase voltammetry and storage of sampled current was performed by computer interfaced to a locally constructed potentiostat operating in two-electrode mode. A potential was applied in $6 \mathrm{mV}$ steps from -100 to $+500 \mathrm{mV}$ versus reference to ensure oxidation of ascorbate and DOPAC. Scan rate was set at $20 \mathrm{mV} / \mathrm{sec}$; scans were run at $1 \mathrm{~min}$ intervals.

Behavioral recording and infusions. Immediately after the working electrode was positioned in striatum, animals were placed for the first time in an open-field arena $\left(1.3 \mathrm{~m}^{2}\right)$ housed inside a sound-attenuating chamber. A lightweight, low-noise cable connected the electrode holder to an electric swivel, allowing the animal complete freedom of movement. A videotaping system recorded behavior for off-line analysis. The behavioral arena was equipped with a variety of novel objects (e.g., metal chains, colored ping-pong balls, plastic wire tubing, rings, dried nuts, etc.) that were changed every few minutes to elicit a rich behavioral repertoire. In some cases, a second rat was placed in the arena for the first time as well to assess social interactions. For these assessments, voltammetry was not performed to allow a full range of social behavior (climbing on top of or underneath the other rat) without interference from cable connections.

Behavior was recorded continuously by an independent observer monitoring videotapes. The observer noted individual items of behavior and entered the appropriate code on a computer keyboard. A computer program summarized the temporal occurrences of each behavioral item and provided a summary histogram in time bins of $\sim 10 \mathrm{sec}$. Individual behavioral responses were subsequently grouped into one of several categories adapted from a previously established paradigm (Wang and Rebec, 1998). The first category was termed motor activation and included movement not directed at other objects or the other rat such as self-grooming, head movement (turning or bobbing), forward locomotion, and rearing. Approach behavior comprised the second category and included moving toward, touching, or playing with novel objects. When another rat was present, a category of social behavior was included in the scoring, and the infused rat was monitored for licking, crawling underneath or on top of, or moving toward the second rat. The final behavioral category, designated as quiet rest, was characterized by periods of no overt movement. The percent time spent in each behavioral category was calculated for specified periods; for each period, the sum of all four categories equaled $100 \%$.

After sufficient time to establish stable behavioral and voltammetric recordings ( $\sim 10 \mathrm{~min})$, baseline data were collected for $20 \mathrm{~min}$. The stylet then was removed from the right cannula, and a 30 gauge infusion needle, connected to an infusion pump via polyethylene tubing, was manually lowered to an area of striatum $\sim 4.0 \mathrm{~mm}$ ventral to the brain surface. The infusion pump was activated, and after $5 \mathrm{~min}$, the needle was advanced $1.0 \mathrm{~mm}$, and the inf usion continued for another $5 \mathrm{~min}$. This two-stage infusion ensured coverage over at least $1.0 \mathrm{~mm}$ of dorsoventral distance. The needle remained in place for $\sim 1.0 \mathrm{~min}$, after which it was removed and the entire process was repeated for the left striatum. The infusion rate was set at $10 \mu \mathrm{l} / \mathrm{hr}$, resulting in a total bilateral infusion volume of $3.3 \mu \mathrm{l}$

Voltammetric recordings, which were always made from the right striatum, continued throughout the infusion process along with behavioral assessments. The position of the working electrode was calculated to allow recording within $500 \mu \mathrm{m}$ of the tip of the infusion track. The animals, previously habituated to the presence of the experimenter (see above), showed normal behavioral patterns during the entire infusion procedure. Both voltammetric and behavioral data were collected for at least $35 \mathrm{~min}$ after infusion offset. In some cases, the infusion was immediately followed by injection (subcutaneous) of $1.0 \mathrm{mg} / \mathrm{kg}$ $d$-amphetamine or vehicle.

For infusions into dorsal hippocampus, the infusion needle was inserted into the right cannula and advanced to a location $\sim 3.0 \mathrm{~mm}$ ventral to the brain surface. The infusion continued at this site for $10 \mathrm{~min}$, and the process was repeated on the left side to mimic both the right-left inf usion sequence and the infusion duration established for the striatum.

Upon completion of recording, each rat was deeply anesthetized with chloropent. Whenever possible, the working electrode was removed for subsequent postcalibration in a solution containing $100 \mu \mathrm{M}$ ascorbate and $20 \mu \mathrm{M}$ DOPAC. The postcalibration step provided a basis for estimating extracellular ascorbate and DOPAC levels in vivo as in previous work (Pierce et al., 1992). After transcardial perfusion with formosaline, the brain was removed, frozen, sectioned, and stained with cresyl violet for histological analysis. For some cases without voltammetry, the perfusion step was performed at least $24 \mathrm{hr}$ after intrastriatal infusion to allow for histological detection of hypoxic injury.

Drugs. $d$-Amphetamine sulfate (Sigma, St. Louis, MO) was mixed in physiological saline $(0.9 \% \mathrm{NaCl})$ and injected subcutaneously as the free base $(1.0 \mathrm{mg} / \mathrm{kg})$. For infusions of AAO (Sigma), 1000 units $(1.0 \mathrm{mg}$ of protein) were dissolved in $5.0 \mathrm{ml}$ of $0.9 \% \mathrm{NaCl}$ immediately before use. Vehicle alone was administered for control injections and infusions. Because AAO may disrupt striatal functioning as a result of its relatively large size as a glycoprotein $\left(\mathrm{M}_{\mathrm{r}}\right.$ of 140,000$)$, we included a second control in which we infused inactive AAO. To inactivate the enzyme, AAO was placed in solution and stored at $>4^{\circ} \mathrm{C}$ for $>48 \mathrm{hr}$ before use. Such treatment inactivates the enzyme (MacCarrone et al., 1993), which we confirmed by in vitro voltammetric testing.

Data analysis. An ANOVA was used to assess the postinfusion change in ascorbate and DOPAC, followed by post hoc analysis with Scheffè $F$ tests. Percent of each behavioral category for preinfusion and postinfusion periods and after amphetamine administration was assessed with a two-tailed, Student's $t$ test.

\section{RESULTS}

Data were obtained from 77 animals prepared for acute bilateral infusions of either AAO or vehicle into striatum or dorsal hippocampus.

\section{Striatum}

A total of 63 animals received four sequential inf usions each (two per side) to ensure relatively widespread coverage of anterior striatum. A composite of all striatal infusion sites, based on subsequent histological analysis, is shown schematically in Figure 


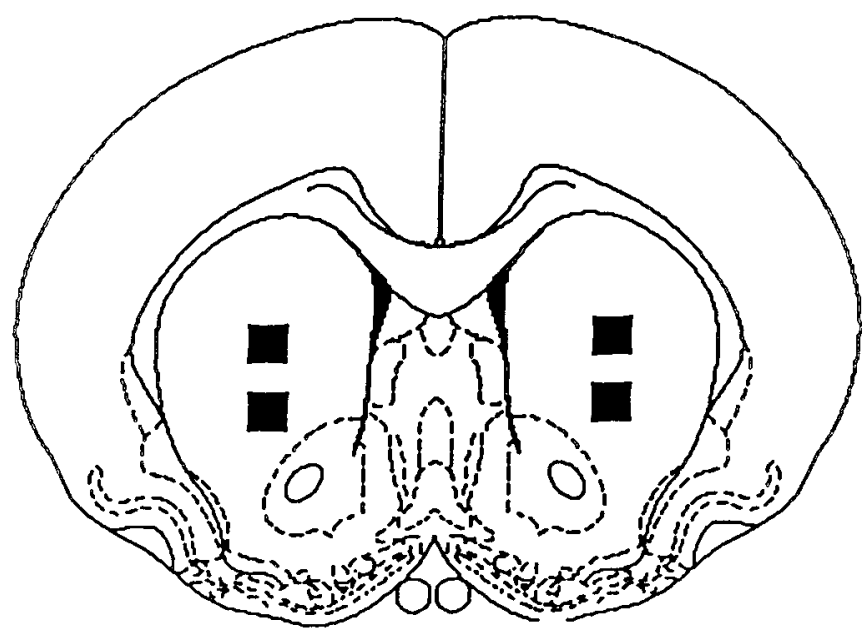

Figure 1. Schematic representation of bilateral infusion sites (2 per side) in anterior striatum. Black squares indicate the composite location of all striatal infusion sites depicted in a coronal section $1.0 \mathrm{~mm}$ anterior to bregma (Paxinos and Watson, 1997). Electrodes for voltammetric recording were positioned unilaterally and lowered to an area calculated to be within $\sim 500 \mu \mathrm{m}$ of the dorsal and ventral infusion sites.

1. Approximately half of the animals $(n=32)$ also were prepared for unilateral, simultaneous voltammetric recording at a site approximately midway between the two ipsilateral infusion sites. These animals did not differ from their nonrecording counterparts on any behavioral measure and thus were combined for all relevant behavioral analyses.

Because AAO uses ascorbate as a cofactor in the enzymatic conversion of molecular oxygen to water, there is the possibility of oxygen depletion and subsequent cell loss as a result of hypoxic injury. Histological assessment of striatal tissue obtained 1 or $2 \mathrm{~d}$ after AAO or saline infusion, however, indicated no evidence of cell damage other than that typically observed along the infusion tract. Sample photomicrographs of striatal tissue at $\sim 500 \mu \mathrm{m}$ from control and AAO infusion sites are shown in Figure 2.

\section{Voltammetry}

As shown for a representative case in Figure 3, all voltammetric signals were characterized by peaks of oxidation current at 100 and $220 \mathrm{mV}$ versus reference, which represent ascorbate and DOPAC oxidation, respectively (Gonon et al., 1981; Crespi et al., 1984). Peak amplitudes remained stable throughout $20 \mathrm{~min}$ of baseline recording. Mean \pm SEM basal concentrations of ascorbate and DOPAC were estimated at $274 \pm 39$ and $29 \pm 5 \mu \mathrm{M}$, respectively, based on successful postcalibration testing $(n=9)$. These values are consistent with other reports using similar recording techniques (Gonon et al., 1980; Stamford et al., 1984; Ghasemzedah et al., 1991).

The amplitude of the ascorbate signal decreased markedly after intrastriatal AAO (Fig. 3). Within 20 min after inf usion offset, a decline of at least $70 \%$ was evident in all animals $(n=12)$. Infusion of the saline vehicle, in contrast, had no effect on the ascorbate signal $(n=9)$. In fact, control animals showed a slow decline characteristic of a gradual loss of electrode sensitivity and slight local depletion from voltammetric oxidation of ascorbate. The time course of the change in the ascorbate signal for both groups is shown in Figure 4. An ANOVA indicated a significant effect of AAO $(p<0.05)$. Subsequent post hoc analysis revealed that, relative to control, the ascorbate decline began soon after infusion and remained significantly below control levels for the duration of postinfusion recording $(p<0.05)$.

The amplitude of the DOPAC signal remained stable after AAO infusion. As shown in Figure 5, the DOPAC response paralleled that obtained from the vehicle group.

\section{Behavior}

All rats were behaviorally active throughout the $20 \mathrm{~min}$ baseline period immediately before infusion onset. The regular introduction of new objects ensured not only multiple episodes of approach behavior (responses aimed directly at the novel objects) but also a relatively stable level of motor activation (open-field locomotion, rearing, head movements, and self-grooming). In all animals, between 40 and $50 \%$ of all behavioral observations during the baseline period were classified as motor activation. Approach behavior accounted for another 5-10\%. The remaining time was spent in quiet rest. For nine animals in which the behavioral paradigm included another rat, the frequency of motor activation and approach behavior did not change, but there were fewer episodes of quiet rest because social behavior accounted for an additional $5-10 \%$ of all behavioral observations. Social responses were typically manifest as touching or licking the second rat.

Vehicle controls maintained baseline levels of responsiveness throughout the behavioral recording period. Similar results were obtained in one case in which inactive AAO was infused, arguing against a nonspecific glycoprotein effect. In contrast, intrastriatal AAO caused a marked drop in the frequency of all behavioral categories, which was evident immediately after infusion offset. The time course of percent total behavior for both a vehicle and AAO infusion is plotted in Figure 6. Note that, like the decline in ascorbate, the AAO-induced behavioral change emerges rela-
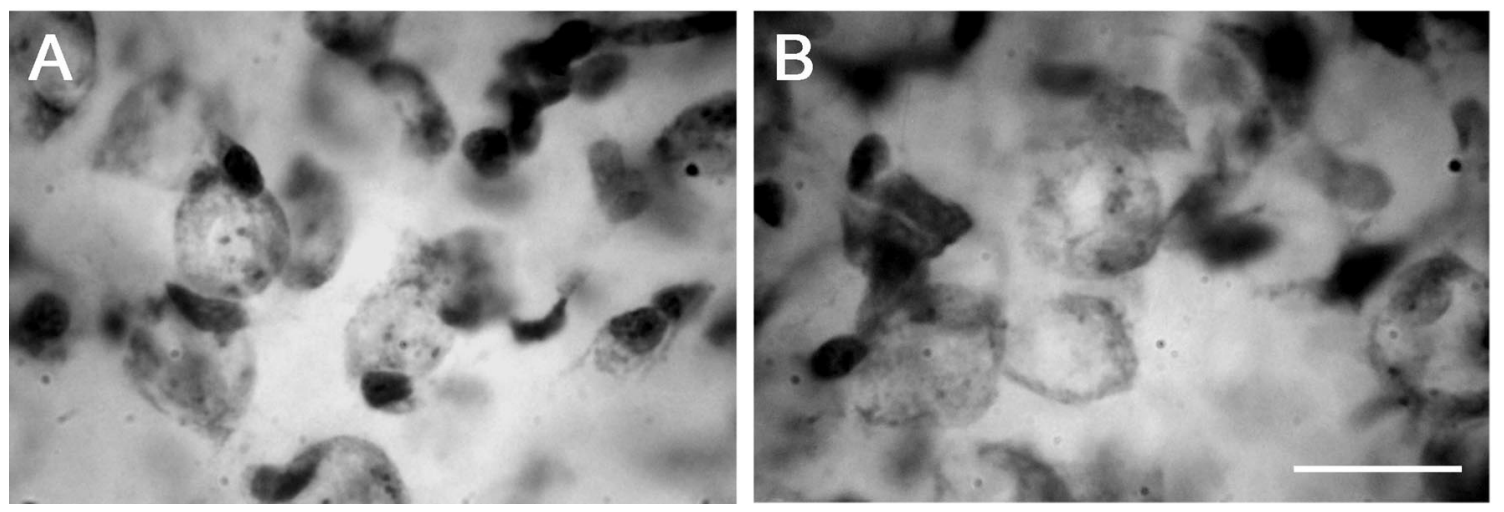

Figure 2. Photomicrographs of pseudorandomly selected striatal fields $\sim 500 \mu \mathrm{m}$ lateral to the ventral infusion site. Coronal sections were obtained 24 $\mathrm{hr}$ after inf usion of either AAO $(A)$ or saline vehicle $(B)$ and stained with cresyl violet. Note the lack of dead or damaged neurons in both sections. Scale bar, $20 \mu \mathrm{m}$. 


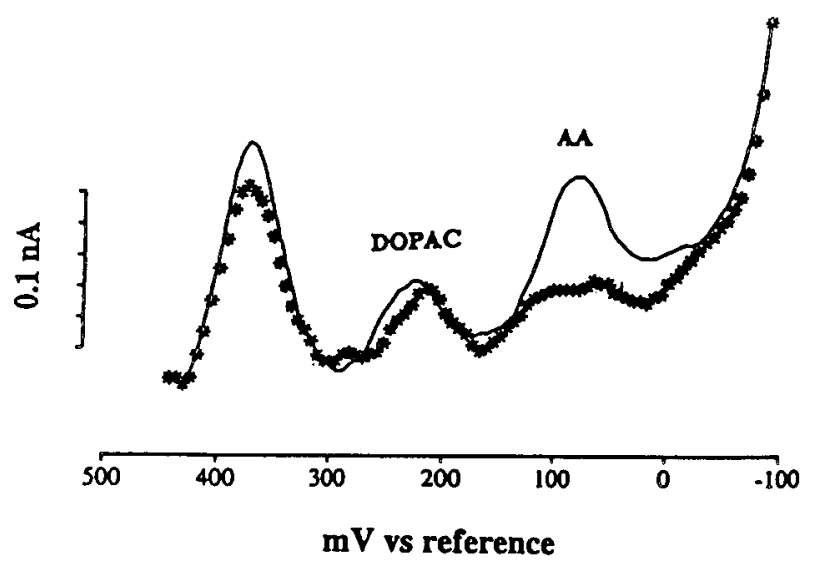

Figure 3. Representative voltammetric scans obtained with an electrochemically pretreated carbon-fiber electrode in anterior striatum of a freely behaving rat. The solid line indicates a scan obtained $10 \mathrm{~min}$ before the onset of an ipsilateral infusion of AAO. Note the distinct peaks for ascorbate $(A A)$ and DOPAC. The scan represented by asterisks was obtained $10 \mathrm{~min}$ after the infusion sequence was completed. Note the decline in the AA peak with relatively little change in DOPAC.

tively rapidly and persists for the duration of the recording session.

As shown in Figure 7, group scores for post-AAO motor activation, approach, and social behavior were almost completely eliminated. Individual $t$ tests revealed a significant difference from baseline values for all three behavioral categories $(p<$ $0.05)$. Episodes of simple movement, when they occurred, were limited to brief $(<5 \mathrm{sec})$ bouts of head bobbing or turning. No grooming, locomotion, or rearing was observed in any of these animals by $25 \mathrm{~min}$ after the AAO infusion. In fact, the animals

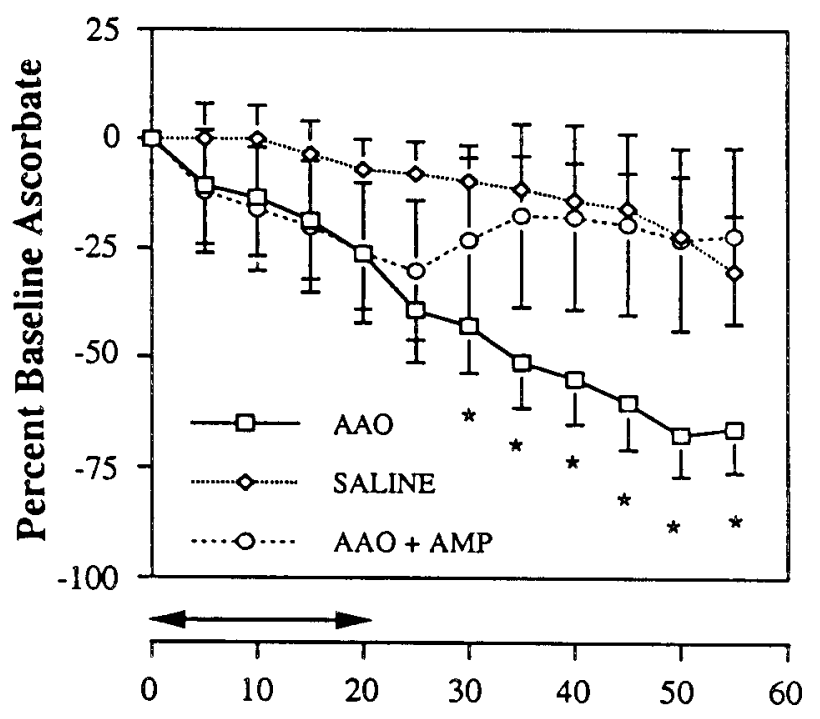

Time (min)

Figure 4. Time course of change in striatal extracellular ascorbate in animals receiving local infusions of AAO $(n=12)$ or saline vehicle $(n=$ 9) as indicated in the legend. Data are presented as the mean \pm SEM percent change from a $10 \mathrm{~min}$ baseline period immediately before infusion onset. Horizontal arrows indicate total infusion time. ${ }^{*} p<0.05$ indicates significantly different from vehicle infusion. Note the AAOinduced progressive decline in ascorbate relative to vehicle controls and the prevention of this effect in animals $(n=11)$ that received (subcutaneous) $1.0 \mathrm{mg} / \mathrm{kg} d$-amphetamine $(A M P)$ immediately after infusion offset at $20 \mathrm{~min}$.

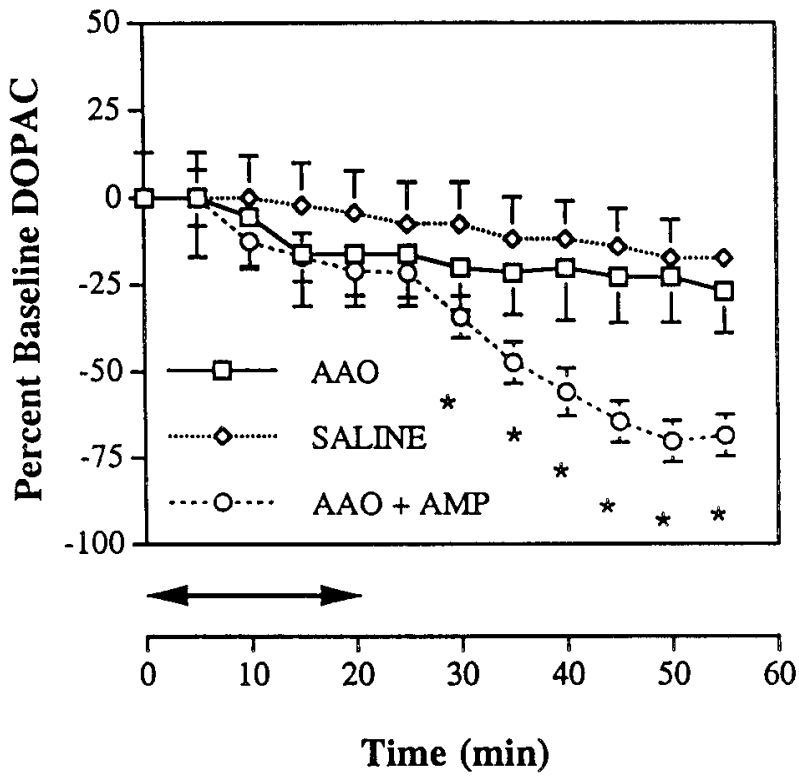

Figure 5. Time course of change in striatal extracellular DOPAC in animals receiving local infusions of AAO $(n=12)$ or saline vehicle $(n=$ 9) as indicated in the legend. Data are presented as in Figure 3. In this case, AAO had no effect on DOPAC, but subsequent subcutaneous injection of $1.0 \mathrm{mg} / \mathrm{kg} d$-amphetamine $(A M P)$ after AAO infusion $(n=$ 11) caused a significant DOPAC decline relative to the vehicle infusion group; * $p<0.05$.

were severely unresponsive, failing to show any interaction with or movement toward novel objects or other rats.

\section{Effects of amphetamine}

Additional animals $(n=11)$ received a subcutaneous injection of $1.0 \mathrm{mg} / \mathrm{kg} d$-amphetamine $(n=11)$ immediately after the AAO infusion. Within $20 \mathrm{~min}$ after injection, the drug reversed the ascorbate decline and restored the extracellular level to preinfusion values (Fig. 4). In fact, the post-amphetamine increase in extracellular ascorbate represented a $>50 \%$ rise above the level established by AAO. As an injection control, some rats in the AAO inf usion group received subcutaneous saline $(n=3)$. These animals showed an ascorbate loss comparable with that of noninjected animals, and thus the data were combined into a single AAO group (Fig. 4).

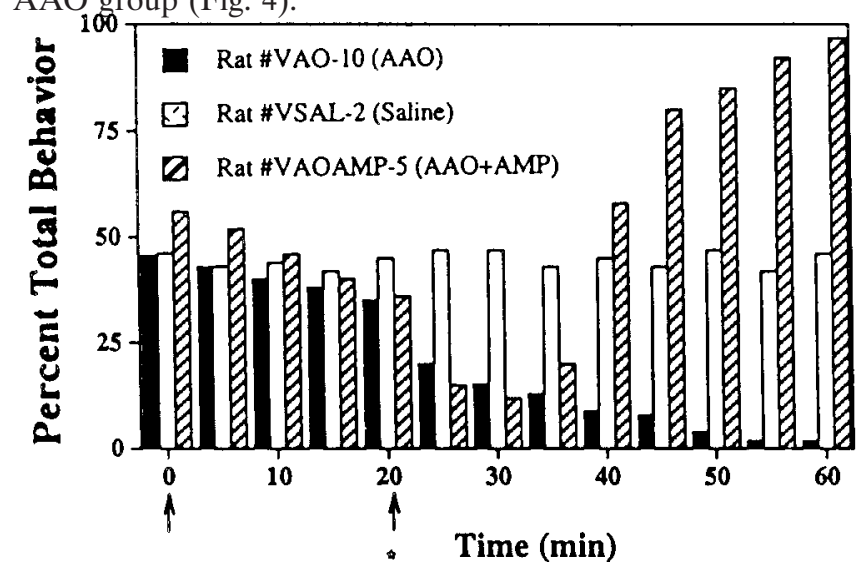

Figure 6. Time course of changes in total behavior in three representative animals that received either intrastriatal AAO or saline or intrastriatal AAO followed by amphetamine $(A M P)$ as indicated in the legend. The first and second arrows indicate the onset and offset, respectively, of the bilateral infusion sequence. The asterisk below the second arrow indicates the time of the AMP injection. Note that, whereas behavior remains stable after vehicle infusion, AAO causes a near-total suppression of behavior that begins shortly after infusion offset. AMP reverses the AAO effect and elicits almost continuous behavioral activation. 


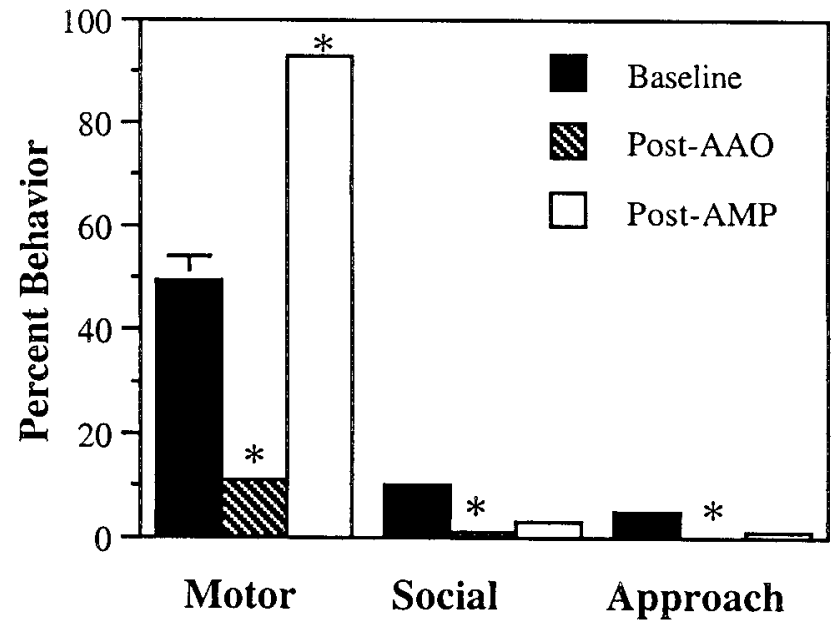

Figure 7. Frequency of expression of motor, social, and approach behavior in all rats during the $20 \mathrm{~min}$ period before (Baseline) and after (Post-AAO) completion of bilateral AAO infusion in anterior striatum as indicated in the legend. Data are presented as mean \pm SEM percent behavior. Motor activation accounts for approximately half of all behavioral observations during baseline, and this value declines dramatically after AAO. Social and approach behaviors account for considerably less baseline behavior, but AAO causes a similar dramatic decline in each. Subsequent subcutaneous injection of $1.0 \mathrm{mg} / \mathrm{kg} d$-amphetamine (Post$A M P)$ reverses the AAO-induced decline in social and approach behavior and elevates motor activation above baseline levels. ${ }^{*} p<0.05$ indicates significantly different from baseline.

Concomitant with the change in ascorbate, amphetamine counteracted the behavioral effect of AAO (Figs. 6, 7). Motor activation, for example, returned to baseline levels within 20 min after amphetamine and significantly surpassed this mark by the end of the recording session. The AAO-induced decline in approach and social behavior also was reversed by amphetamine but not above the preinfusion baseline level.

As an indirect dopamine agonist, amphetamine releases intracellular dopamine and thus decreases intracellular DOPAC production (Kuczenski and Segal, 1994). Our results confirm this effect (Fig. 5). A repeated measures ANOVA revealed a significant amphetamine-induced effect on DOPAC $(p<0.05)$. Post hoc comparisons indicated a significant DOPAC decline shortly after drug injection $(p<0.05)$.

\section{Dorsal hippocampus}

A separate group of 14 animals received bilateral infusions of AAO in dorsal hippocampus at the same rate and duration used for intrastriatal infusions. As shown in Figure 8, despite consistent bilateral placement, hippocampal AAO had no significant behavioral effect. Categories of motor activation, approach, and social behavior persisted at frequencies comparable with those established during the baseline period. These results argue against a generalized behavioral deficit caused by a brain ascorbate loss and help to establish a specific role for striatal ascorbate in this effect.

\section{DISCUSSION}

The ability of the striatum to process cognitive, emotional, and motor information requires a functional balance among amino acid, peptide, and monoamine transmitters (Hauber, 1998). Disruption of this balance by either experimental manipulation or disease can lead to profound behavioral disturbances (Albin et al., 1989). Ascorbate is commonly viewed as an antioxidant, protecting against the accumulation of toxic free radicals (Ghosh et al., 1996; Noctor and Foyer, 1998). Its high concentration in striatal extracellular fluid (considerably higher than that of any of the known transmitters) is consistent with this view (BasseTomusk and Rebec, 1991). Increasing evidence, however, has begun to broaden the functional role of ascorbate (Rebec and Pierce, 1994; Rice, 2000), and we now build on this evidence to report that extracellular ascorbate in the striatum is necessary for normal behavioral output.

\section{AAO-induced depletion of extracellular ascorbate}

Within minutes after local application of AAO, we recorded a $>50 \%$ decline in the extracellular level of striatal ascorbate. In fact, the level remained low for the duration of the recording session, indicating that the depletion was not readily overcome by release from intracellular stores. This is an interesting finding in view of in vitro evidence that the brain maintains extracellular ascorbate within relatively strict limits at the expense of an intracellular supply (Schenk et al., 1982). In fact, neurons have been reported to sequester up to 10 times more ascorbate than glia (Rice and Russo-Menna, 1998), implicating neuronal mechanisms in the homeostatic control of extracellular ascorbate levels. Such control, however, may operate over a relatively long time course because the AAO-induced ascorbate depletion was still evident in ipsilateral striatum at 50 min after infusion offset. Because AAO did not block amphetamine-induced ascorbate
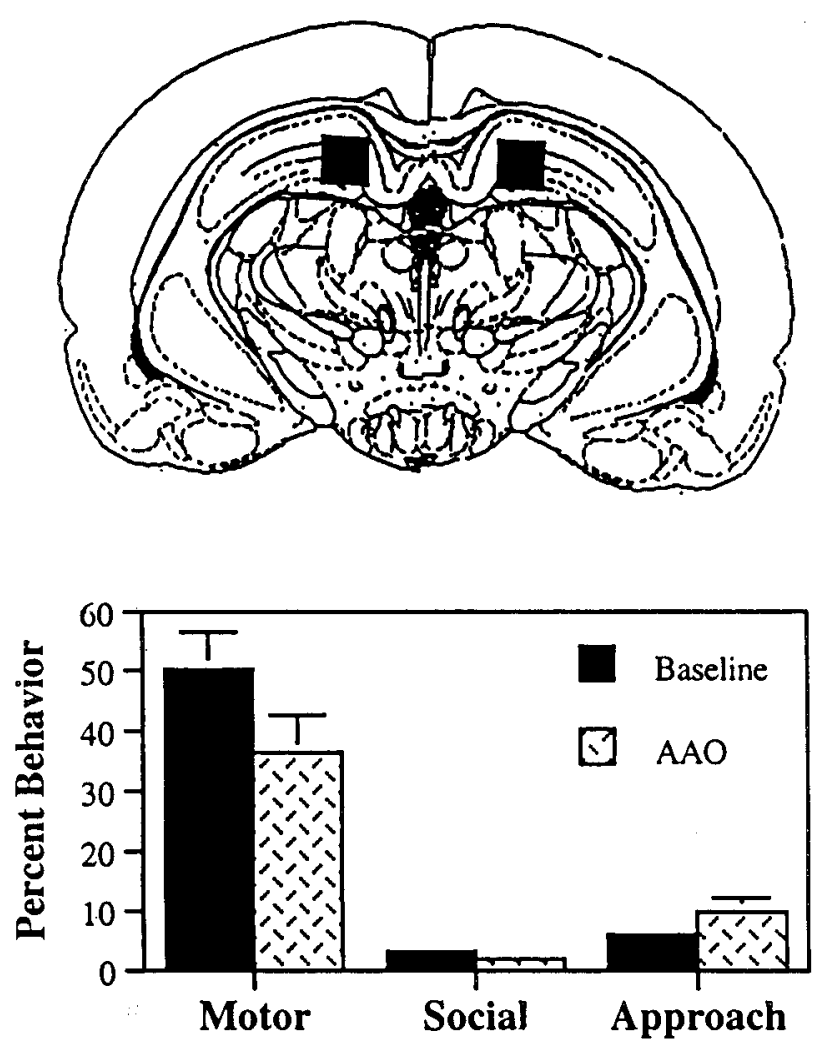

Figure 8. AAO inf usion sites in dorsal hippocampus (top) and frequency of expression of motor, social, and approach behavior during the $20 \mathrm{~min}$ period before (Baseline) and after local, bilateral infusion of AAO (bottom). Top, Composite, schematic representation of bilateral AAO infusion sites $(n=14)$ in a coronal section $4.5 \mathrm{~mm}$ posterior to bregma (Paxinos and Watson, 1997). Bottom, Frequency of expression of each behavioral category as presented in Figure 7. Note the lack of behavioral change. 
release, it seems unlikely that the loss of extracellular ascorbate also depleted intracellular stores.

The ascorbate response to amphetamine does not involve a peripheral mechanism because the effect is neither blocked by adrenalectomy, which removes a major source of peripheral ascorbate, nor mimicked by $p$-hydroxy-amphetamine, a peripheral sympathomimetic (Wilson and Wightman, 1985). Surprisingly, dopaminergic terminals in the striatum also are an unlikely source of amphetamine-induced ascorbate release because this effect persists even after near-total destruction of dopaminergic terminals (Kamata et al., 1986). Amphetamine-induced ascorbate release appears to depend, instead, on corticostriatal neurons. Cortical damage, for example, not only lowers basal ascorbate levels in the striatum but also attenuates amphetamine-induced release of ascorbate (Basse-Tomusk and Rebec, 1990). This finding is consistent with evidence that glutamate, which is released by corticostriatal neurons, plays a key role in striatal ascorbate release (Grünewald and Fillenz, 1984). According to a popular model (Fillenz et al., 1986; O’Neill, 1995), glutamate uptake from extracellular fluid results in ascorbate heteroexchange. Thus, an increase in the activity of glutamatergic neurons causes an increase in extracellular ascorbate. In support of this model, amphetamine has been shown to increase glutamate release in striatal tissue (Nash and Yamamoto, 1993; Wang and McGinty, 1999), and an increase in extracellular glutamate is a prerequisite for an increase in extracellular ascorbate (Pierce and Rebec, 1993; Miele et al., 1994; Lai et al., 2000). It seems likely, therefore, that amphetamine reverses the effect of AAO by releasing ascorbate from corticostriatal terminals.

\section{Functional implications of a loss of extracellular ascorbate}

An ascorbate-glutamate heteroexchange system ensures a high level of extracellular ascorbate during periods of glutamatergic activity. As an antioxidant, ascorbate may protect against the overproduction of free radicals, which can result from glutamateinduced activation of NMDA receptors (Coyle and Puttfarcken, 1993). Thus, removal of ascorbate from extracellular fluid by AAO may increase susceptibility to oxidative damage. It seems unlikely, however, that this effect can explain the behavioral deficits induced by AAO given their rapid onset and their equally rapid reversal by amphetamine. Consistent with this conclusion, we saw no histological evidence of hypoxic injury. AAO also failed to alter striatal DOPAC, arguing against a disruption of dopamine transmission. The decline in DOPAC after amphetamine, moreover, is consistent with a fully functioning dopaminergic system and confirms the action of this drug as an indirect dopamine agonist (Seiden et al., 1993; Kuczenski and Segal, 1994). In fact, our behavioral results with amphetamine rule out the possibility that AAO binds to either dopamine receptors or the dopamine molecule to inhibit behavior.

Ascorbate may play a direct role in striatal information processing by modulating glutamate function. In awake rats, for example, ascorbate iontophoresis enhances the magnitude of glutamate-induced neuronal excitations (Kiyatkin and Rebec, 1998). This effect, moreover, is not shared by the nonbiological isomer of ascorbate, despite comparable redox potentials. Thus, a loss of endogenous ascorbate may impair striatal glutamate transmission independently of a change in antioxidant protection.

Fluctuations in striatal ascorbate also are likely to modulate dopamine function, but the direction of effect depends critically on ascorbate concentration. Injection of a high systemic (Rebec et al., 1985) or intrastriatal (White et al., 1990) dose has a dopamine antagonist effect on behavior, opposing the action of amphetamine and enhancing that of haloperidol. At relatively low doses, however, ascorbate has been reported to potentiate amphetamine-induced behavioral activation (Wambebe and Sokomba, 1986) and conditioned place preference (Pierce et al., 1995). Similarly, low-dose application of ascorbate enhances the electrophysiological action of dopamine on motor-related neurons in the striatum (Pierce and Rebec, 1995), whereas high doses have a marked suppressive effect (Gardiner et al., 1985; Kiyatkin and Rebec, 1998). Our results with AAO suggest that ascorbate, in its normal range of extracellular concentrations, plays a critical facilitative role on behavior, perhaps by enhancing dopamine transmission.

Although the mechanism remains unclear, one possibility is a direct action on the dopamine receptor. Despite inconsistencies in the literature (for review, see Rebec and Pierce, 1994), this hypothesis continues to receive experimental support. In retinal slices, for example, relatively small increases in extracellular ascorbate have a positive modulating effect on voltage-gated potassium currents by D1 dopamine receptors (Fan and Yazulla, 1999). Alternatively, as an antioxidant, ascorbate may prolong the life of dopamine in extracellular fluid. This mechanism appears to operate in the retina in which dopamine is believed to diffuse between neuronal layers (Neal et al., 1999). Interestingly, dopamine may diffuse over relatively long distances in the striatum (Gonon et al., 1991; Garris et al., 1994). Anatomical evidence supports this view (Nirenberg et al., 1996) and even suggests a mechanism for a permanent level of dopamine in extracellular fluid (Descarries et al., 1996). Extracellular diffusion would allow for dopamine not only to interact with receptors on presynaptic terminals but also to exert distant effects on astrocytes and microvessels (Agnati et al., 1995; Zoli et al., 1998). Ascorbate may facilitate this process by protecting dopamine against oxidative attack by various constituents of striatal extracellular fluid. If this is the case, then the behavioral effects of intrastriatal AAO may represent a temporary disruption of extrasynaptic dopamine diffusion. The failure to detect an AAO-induced change in DOPAC does not rule out this hypothesis because DOPAC is derived primarily from metabolism of cytoplasmic rather than extracellular dopamine (Zetterstrom et al., 1986; Kuczenski and Segal, 1989). Certainly, the dramatic loss of responsiveness in all behavioral categories after intrastriatal AAO parallels the global behavioral deficits characteristic of a large striatal dopamine depletion (Schultz, 1982; Sakai and Gash, 1994). Moreover, amphetamine, which is known to elevate extracellular dopamine (Kuczenski and Segal, 1994), reverses these behavioral effects. Noteworthy from a clinical perspective is evidence that extrasynaptic diffusion of dopamine contributes to behavioral recovery from the dopamine deficits induced by experimental parkinsonism (Schneider et al., 1994; Zigmond, 1994; Garris et al., 1997). Although it is not clear whether endogenous ascorbate plays a role in this parkinsonian plasticity, it seems likely that the behavioral deficits after intrastriatal AAO involve a dopaminergic component.

Like the striatum, dorsal hippocampus has a high level of extracellular ascorbate sensitive to AAO (Ghasemzedah et al., 1991). Because the factors controlling ascorbate distribution across brain regions are unknown, it is possible that the behavioral deficits we report are not unique to a loss of striatal ascorbate but reflect a disruption of ascorbate homeostasis throughout the brain caused by a deficit in one region. Our intrahippocampal 
infusions argue against this possibility. Of course, hippocampal ascorbate itself may play a critical behavioral role, but this hypothesis is best tested with a paradigm sensitive to hippocampal function. Interestingly, striatal and hippocampal ascorbate differ in their ability to protect against global ischemia (Stamford et al., 1999), supporting the suggestion that region-specific changes in extracellular ascorbate may have unique functional consequences.

\section{Conclusions}

Our results show that depletion of ascorbate from striatal extracellular fluid has a broad suppressive effect on behavior. Extracellular DOPAC remains stable, suggesting an intact dopaminergic system, and subsequent injection of amphetamine reverses both the loss of ascorbate and the behavioral suppression. These data, combined with previous reports of striatal ascorbate release during behavior (O'Neill and Fillenz, 1985; Pierce and Rebec, 1990; Zetterstrom et al., 1992), suggest a requirement for extracellular ascorbate in behavioral activation. The mechanisms underlying this role may involve modulations of glutamate or dopamine transmission, both of which appear to function in close relation to striatal ascorbate release. Although further work is required to assess these interactions, the level of extracellular ascorbate is critically involved in striatal control of behavioral output.

\section{REFERENCES}

Agnati LF, Zoli M, Stromberg I, Fuxe K (1995) Intercellular communication in the brain: wiring versus volume transmission. Neuroscience 69:711-726.

Albin RL, Young AB, Penny JB (1989) The functional anatomy of basal ganglia disorders. Trends Neurosci 12:366-375.

Basse-Tomusk A, Rebec GV (1990) Corticostriatal and thalamic regulation of amphetamine-induced ascorbate release in the neostriatum. Pharmacol Biochem Behav 35:55-60.

Basse-Tomusk A, Rebec GV (1991) Regional distribution of ascorbate and 34-dihydroxyphenylacetic acid (DOPAC) in rat neostriatum. Brain Res 538:29-35.

Calabresi P, Demurtas M, Bernardi G (1997) The neostriatum beyond the motor function: experimental and clinical evidence. Neuroscience 78:39-60.

Cammack J, Ghasemzadeh B, Adams RN (1991) The pharmacological profile of glutamate-evoked ascorbic acid efflux measured by in vivo electrochemistry. Brain Res 565:17-22.

Coyle JT, Puttfarcken P (1993) Oxidative stress glutamate and neurodegenerative disorders. Science 262:689-695.

Crespi F, Sharp T, Maidement NT, Marsden CA (1984) Differential pulse voltammetry: simultaneous in vivo measurement of ascorbic acid catechols and 5-hydroxyindoles in the rat striatum. Brain Res 332:135-138.

Descarries L, Watkins KC, Garcia S, Bosler O, Doucet G (1996) Dual character asynaptic and synaptic of the dopamine innervation in adult rat neostriatum: a quantitative autoradiographic and immunocytochemical analysis. J Comp Neurol 375:167-186.

Ewing AG, Wightman RM, Dayton MA (1982) In vivo voltammetry with electrodes that discriminate between dopamine and ascorbate. Brain Res 249:361-370.

Fan SF, Yazulla S (1999) Modulation of voltage-dependent K ${ }^{+}$currents $(\mathrm{I}-\mathrm{K}(\mathrm{V}))$ in retinal bipolar cells by ascorbate is mediated by dopamine D1 receptors. Visual Neurosci 16:923-931.

Fillenz M, O’Neill RD, Grünewald RA (1986) Changes in extracellular brain ascorbate concentration as an index of excitatory aminoacid release. In: Monitoring neurotransmitter release during behaviour (Joseph MH, Fillenz M, MacDonald IA, Marsden CA, eds), pp 144-163. Chichester, UK: Norwood.

Gardiner TW, Armstrong-James M, Caan AW, Wightman RM, Rebec GV (1985) Modulation of neostriatal unit activity by iontophoresis of ascorbic acid. Brain Res 344:181-185.

Garris PA, Ciolkowski EL, Pastore P, Wightman RM (1994) Efflux of dopamine from the synaptic cleft in the nucleus accumbens of the rat brain. J Neurosci 14:6084-6093.

Garris PA, Walker QD, Wightman RM (1997) Dopamine release and uptake rates both decrease in the partially denervated striatum in proportion to the loss of dopamine terminals. Brain Res 753:225-234.

Gerfen CR, Wilson CJ (1996) The basal ganglia. In: Handbook of chem- ical neuroanatomy (Swanson LW, Björklund A, Hökfelt T, eds), pp 371-468. Amsterdam: Elsevier.

Ghasemzedah B, Cammack J, Adams RN (1991) Dynamic changes in extracellular fluid ascorbic acid monitored by in vivo electrochemistry. Brain Res 547:162-166.

Ghosh MK, Chattopadhyay DJ, Chatterjee IB (1996) Vitamin C prevents oxidative damage. Free Radical Res 6 25:173-179.

Gonon F, Buda M, Cespuglio R, Jouvet M, Pujol JF (1980) In vivo electrochemical detection of catechols in the neostriatum of anaesthetized rats: dopamine or DOPAC? Nature 286:902-904.

Gonon F, Buda M, Cespuglio R, Jouvet M, Pujol JF (1981) Voltammetry in the striatum of chronic freely moving rats: detection of catechols and ascorbic acid. Brain Res 223:69-80.

Gonon FG, Suaud-Chagny MF, Mermet CC, Buda M (1991) Relation between impulse flow and extracellular catecholamine levels as studied by in vivo electrochemistry in CNS. In: Volume transmission in the brain: novel mechanisms for neural transmission (Fuxe K, Agnati LF, eds), pp 337-350. New York: Raven.

Graybiel AM, Aosaki T, Flaherty AW, Kimura M (1994) The basal ganglia and adaptive motor control. Science 265:1826-1831.

Grünewald RA, Fillenz M (1984) Release of ascorbate from synaptosomal fraction of rat brain. Neurochem Int 6:491-500.

Halliwell B (1996) Antioxidants in human health and disease. Annu Rev Nutr 16:33-50.

Hauber W (1998) Involvement of basal ganglia transmitter systems in movement initiation. Prog Neurobiol 56:507-540.

Kamata K, Wilson RL, Alloway KD, Rebec GV (1986) Multiple amphetamine injections reduce the release of ascorbic acid in the neostriatum of the rat. Brain Res 362:331-338.

Kaufmann P, Wiens W, Dirks M, Krehbiel D (1986) Changes in social behavior and brain catecholamines during the development of ascorbate deficiency in guinea pigs. Behav Proc 13:13-28.

Kiyatkin EA, Rebec GV (1998) Heterogeneity of ventral tegmental area neurons: single-unit recording and iontophoresis in awake unrestrained rats. Neuroscience 85:1285-1309.

Kuczenski R, Segal D (1989) Concomitant characterization of behavioral and striatal neurotransmitter response to amphetamine using in vivo microdialysis. J Neurosci 9:2051-2065.

Kuczenski R, Segal DS (1994) Neurochemistry of amphetamine. In: Amphetamine and its analogs (Cho A, Segal DS, eds), pp 81-113. San Diego: Academic.

Lai YJ, Shen EY, Pan WHT (2000) Effects of ascorbate in microdialysis perfusion medium on the extracellular basal concentration of glutamate in rat's striatum. Neurosci Lett 279:145-148.

MacCarrone M, Dandrea G, Salucci ML, Avigliano L, Finazziagro A (1993) Temperature, $\mathrm{pH}$ and UV irradiation effects on ascorbate oxidase. Phytochemistry 32:795-798.

Miele M, Boutelle MG, Fillenz M (1994) The physiologically induced release of ascorbate in rat brain is dependent on impulse traffic, calcium influx and glutamate uptake. Neuroscience 62:87-91.

Mueller K (1989) Repeated administration of high doses of amphetamine increases release of ascorbic acid in caudate but not nucleus accumbens. Brain Res 494:30-35.

Nash JF, Yamamoto BK (1993) Effect of $d$-amphetamine on the extracellular concentrations of glutamate and dopamine in iprindole-treated rats. Brain Res 627:1-8.

Neal MJ, Cunningham JR, Matthews KL (1999) Release of endogenous ascorbic acid preserves extracellular dopamine in the mammalian retina. Invest Ophthalmol Vis Sci 40:2983-2987.

Nicola SM, Surmeier DT, Malenka RC (2000) Dopaminergic modulation of neuronal excitability in the striatum and nucleus accumbens. Annu Rev Neurosci 23:185-215.

Nirenberg MJ, Vaughan RA, Uhl GR, Kuhar MJ, Pickel VM (1996) The dopamine transporter is localized to dendritic and axonal plasma membranes of nigrostriatal dopaminergic neurons. J Neurosci 16:436-447.

Noctor G, Foyer CH (1998) Ascorbate and glutathione: keeping active oxygen under control. Ann Rev Plant Physiol Plant Mol Biol 49:249-279.

O'Neill R (1995) The measurement of brain ascorbate in vivo and its link with excitatory amino acid neurotransmission. In: Voltammetric methods in brain systems neuromethods, Vol 27 (Boulton A, Baker G, Adams RN, eds), pp 221-268. Clifton, NJ: Humana.

O'Neill RD, Fillenz M (1985) Circadian changes in extracellular ascorbate in rat cortex accumbens striatum and hippocampus: correlations with motor activity. Neurosci Lett 60:331-336.

O’Neill RD, Fillenz M, Sundstrom L, Rawlins JNP (1984) Voltammetrically monitored brain ascorbate as an index of excitatory amino acid release in the unrestrained rat. Neurosci Lett 52:227-233.

Parent A, Cote PY, Lavoie B (1995) Chemical anatomy of primate basal ganglia. Prog Neurobiol 46:131-197.

Paxinos G, Watson C (1997) The rat brain in stereotaxic coordinates, Ed 3. New York: Academic.

Pierce RC, Rebec GV (1990) Stimulation of both D1 and D2 receptors 
increases behavioral activation and ascorbate release in the neostriatum of freely moving rats. Eur J Pharmacol 191:295-302.

Pierce RC, Rebec GV (1993) Intraneostriatal administration of glutamate antagonists increases behavioral activation and decreases neostriatal ascorbate via non-dopaminergic mechanisms J Neurosci 13:4272-4280

Pierce RC, Rebec GV (1995) Iontophoresis in the neostriatum of awake unrestrained rats: differential effects of dopamine glutamate and ascorbate on motor and nonmotor related neurons. Neuroscience 67:313-324.

Pierce RC, Miller DM, Reising D, Rebec GV (1992) Unilateral neostriatal kainate but not 6-0HDA lesions block dopamine agonistinduced ascorbate release in the neostriatum of freely-moving rats. Brain Res 597:138-143.

Pierce RC, Rowlett JK, Rebec GV, Bardo MT (1995) Ascorbate potentiates amphetamine-induced conditioned place preference and forebrain dopamine release in rats. Brain Res 688:21-26.

Rebec GV, Pierce RC (1994) A vitamin as neuromodulator: ascorbate release into the extracellular fluid of the brain regulates dopaminergic and glutamatergic transmission. Prog Neurobiol 43:537-565.

Rebec GV, Centore JM, White LK, Alloway KD (1985) Ascorbic acid and the behavioral response to haloperidol: implications for the action of antipsychotic drugs. Science 227:438-440.

Rebec GV, Langley PE, Pierce RC, Wang Z, Heidenreich BA (1993) A simple micromanipulator for multiple uses in freely moving rats: electrophysiology voltammetry and simultaneous intracerebral infusions. J Neurosci Methods 47:53-59.

Redgrave P, Prescott TJ, Gurney K (1999) The basal ganglia: a vertebrate solution to the selection problem? Neuroscience 89:1009-1023

Rice ME (2000) Ascorbate regulation and its neuroprotective role in the brain. Trends Neurosci 23:209-216.

Rice ME, Russo-Menna I (1998) Differential compartmentalization of brain ascorbate and glutathione between neurons and glia. Neuroscience 82:1213-1223.

Sakai K, Gash DM (1994) Effect of bilateral 6-ohda lesions of the substantia nigra on locomotor activity in the rat. Brain Res 633:144-150.

Schenk JO, Miller E, Gaddis R, Adams RN (1982) Homeostatic control of ascorbate concentration in CNS extracellular fluid. Brain Res 253:353-356.

Schneider JS, Rothblat DS, Distefano L (1994) Volume transmission of dopamine over large distances may contribute to recovery from experimental Parkinsonism. Brain Res 643:86-91.

Schultz W (1982) Depletion of dopamine in the striatum as an experimental model of Parkinsonism: direct effects and adaptive mechanisms. Prog Neurobiol 18:121-166.
Seiden LS, Sabol KE, Ricaurte GA (1993) Amphetamine: effects on catecholamine systems and behavior. Annu Rev Pharmacol Toxicol 33:639-677.

Spanagel R, Weiss F (1999) The dopamine hypothesis of reward: past and current status. Trends Neurosci 22:521-527.

Stamford JA, Kruk ZL, Millar J (1984) Regional differences in extracellular ascorbic acid levels in rat brain determined by high speed cyclic voltammetry. Brain Res 299:289-295.

Stamford JA, Isaac D, Hicks CA, Ward MA, Osborne DJ, O'Neill MJ (1999) Ascorbic acid is neuroprotective against global ischaemia in striatum but not hippocampus: histological and voltammetric data. Brain Res 835:229-240.

Tsukaguchi H, Tokui T, Mackenzie B, Berger UV, Chen XZ, Wang YX, Brubaker RF, Hediger MA (1999) A family of mammalian $\mathrm{Na}^{+}$dependent L-ascorbic acid transporters. Nature 399:70-75.

Wambebe C, Sokomba E (1986) Some behavioral and EEG effects of ascorbic acid in rats. Psychopharmacology 89:167-170.

Wang JQ, McGinty JF (1999) Glutamate-dopamine interactions mediate the effects of psychostimulant drugs. Addict Biol 4:141-150.

Wang Z, Rebec GV (1998) Neuroethological assessment of amphetamine and neuroleptic drugs in the amygdala and nucleus accumbens: implications for mesolimbic functioning. Prog Biol Psychiatr 22:883-905.

White LK, Maurer M, Kraft ME, Oh C, Rebec GV (1990) Intrastriatal infusions of ascorbate antagonize the behavioral response to amphetamine. Pharmacol Biochem Behav 36:485-489.

Wilson RL, Wightman RM (1985) Systemic and nigral application of amphetamine both cause an increase in extracellular concentration of ascorbate in the caudate nucleus of the rat. Brain Res 339:219-226.

Zetterstrom T, Sharp T, Ungerstedt U (1986) Further evaluation of the mechanism by which amphetamine reduces striatal dopamine metabolism: a brain dialysis study. Eur J Pharmacol 132:1-9.

Zetterstrom T, Wheeler DB, Boutelle MG, Fillenz M (1992) Striatal ascorbate and its relationship to dopamine receptor stimulation and motor activity Eur J Neurosci 3: 940-946.

Zigmond MJ (1994) Chemical transmission in the brain: homeostatic regulation and its functional implications. Prog Brain Res 100:115-122.

Zigmond MJ, Abercrombie ED, Berger TW, Grace AA, Stricker EM (1990) Compensations after lesions of central dopaminergic neurons: some clinical and basic implications. Trends Neurosci 13:290-296.

Zoli M, Torri C, Ferrari R, Jansson A, Zini I, Fuxe K, Agnati LF (1998) The emergence of the volume transmission concept. Brain Res Rev 26:136-147. 